\title{
PROGRESSIVE FAILURE STUDIES OF COMPOSITE PANELS WITH AND WITHOUT CUTOUTS
}

\author{
Damodar R. Ambur* \\ NASA Langley Research Center \\ Hampton, VA 23681-2199 \\ Navin Jaunky ${ }^{\dagger}$ \\ ICASE \\ Hampton, VA 23681-2199 \\ Carlos G. Davila ${ }^{\ddagger}$ and Mark Hilburger ${ }^{\S}$ \\ NASA Langley Research Center \\ Hampton, VA 23681-2199
}

\begin{abstract}
Progressive failure analyses results are presented for composite panels with and without a cutout and are subjected to in-plane shear loading and compression loading well into their postbuckling regime. Ply damage modes such as matrix cracking, fiber-matrix shear, and fiber failure are modeled by degrading the material properties. Results from finite element analyses are compared with experimental data. Good agreement between experimental data and numerical results are observed for most structural configurations when initial geometric imperfections are appropriately modeled.

\section{Introduction}

\footnotetext{
*Head, Mechanics and Durability Branch. Associate Fellow AIAA

†Senior Staff scientist. Member AIAA

$\ddagger$ Aerospace Engineer, Analytical \& Computational Methods Branch. Member AIAA

$\S$ Aerospace Engineer, Mechanics and Durability Branch. Member AIAA

${ }^{1}$ Copyright (C) 2001 by the American Institute of Aeronautics and Astronautics, Inc. No copyright is asserted in the United States under Title 17, U.S code. The U.S Government has a royalty-free license to exercise all rights under the copyright claimed herein for Government Purposes. All other rights are reserved by the copyright owner.
}

The use of composite materials for aircraft primary structures can result in significant benefits on aircraft structural cost and performance. Such applications of composites materials are expected to result in a 30-40 percent weight savings and a 10-30 percent cost reduction compared to conventional metallic structures. However, unlike conventional metallic materials, composite structures fail under different failure modes such as matrix cracking, fiber-matrix shear failure, fiber failure, and delamination. The initiation of damage in a composite laminate occurs when a single ply or part of the ply in the laminate fails in any of these failure modes over a certain area of the structure. The initiation of damage does not mean that the structure cannot carry any additional load. The residual load bearing capability of the composite structure from the onset of material failure or initiation of damage to final failure can be quite significant. It is at the final failure load that the structure cannot carry any further load. This may be due to the fact that some failure modes may be benign not to degrade the performance of the overall structure significantly. Accurate determination of failure modes and their progression helps either to devise structural features for damage containment or to define fail-safe criteria. Therefore it is important to understand the damage progression in 
composite structures subjected to different loading conditions.

Considerable work has been performed on this subject. In 1987, Talreja ([1]), Allen et al. ([2]), and Chang and Chang ([3]), independently proposed progressive failure models that describe the accumulation of damage in a composite laminate by a field of internal state variables. The damage model proposed by Chang and Chang ([3]) for notched laminate loaded in tension accounts for all of the possible failure modes except delamination. Chang and Lessard ([4]) later investigated the damage tolerance of composite laminates subjected to compression. Davila et al. ([5]) extended Chang and Lessard method from two dimensional membrane effects to shellbased analysis that includes bending. Shell-based progressive failure analyses that apply a material degradation model at every material point in every ply in the laminate have been reported in References [6] through [9]. Recently a shellbased progressive failure analysis which considered large rotations based on a total Lagrangian approach method was presented in Reference [10].

The objective of the present paper is to develop and validate an efficient methodology that can predict the ultimate strength of composite panels by taking into account ply damage modes and geometrical non-linear response. Results from progressive failure analyses of composite panels with and without a cutout subjected to shear and compressive loads are compared with experimental results. In this paper progressive failure results are compared with experimental results for flat panels with and without cutout subjected in-plane shear loading. Progressive failure results are also presented for curved panels with and without a cutout and subjected to axial compression. Although results from such experimental studies have been compared by other authors with postbuckling analyses results, progressive failure analyses for nonlinearly deformed structures is not reported in the open literature. Thus another objective for this paper is to provide such a comparison.

\section{Failure Analysis}

Failure modes in laminated composite panels are strongly dependent on ply orientation, loading direction and panel geometry. There are four basic modes of failure that occur in a laminated composite structure. These failure modes are; matrix cracking, fiber-matrix shear failure, fiber failure, and delamination. Delamination failure, however, is not included in the present studies. In order to simulate damage growth accurately, the failure analysis must be able to predict the failure mode in each ply and apply the corresponding reduction in material stiffnesses. The failure criteria included in the present analyses are those proposed by Hashin [11] and are summarized below.

- Matrix failure in tension and compression occurs due to a combination of transverse, $\sigma_{22}$, and shear stress, $\tau_{12}, \tau_{13}$ and $\tau_{23}$. The failure index can be defined in terms of these stresses and the strength parameters $Y$ and shear allowables $S_{c}$. Failure occurs when the index exceeds unity. Assuming linear elastic response, the failure index has the form:

$$
\begin{aligned}
e_{m}^{2} & =\frac{\sigma_{22}}{Y_{c}}\left[\left(\frac{Y_{c}}{2 S_{c 23}}\right)^{2}-1\right]+\left(\frac{\sigma_{22}}{2 S_{c 23}}\right)^{2} \\
& +\left(\frac{\tau_{12}}{S_{c 12}}\right)^{2}+\left(\frac{\tau_{13}}{S_{c 13}}\right)^{2} \\
& +\left(\frac{\tau_{23}}{S_{c 23}}\right)^{2} \text { for } \sigma_{22}<0
\end{aligned}
$$

and

$$
\begin{aligned}
e_{m}^{2} & =\left(\frac{\sigma_{22}}{Y_{t}}\right)^{2}+\left(\frac{\tau_{12}}{S_{c 12}}\right)^{2}+\left(\frac{\tau_{13}}{S_{c 13}}\right)^{2} \\
& +\left(\frac{\tau_{23}}{S_{c 23}}\right)^{2} \text { for } \sigma_{22}>0
\end{aligned}
$$

where $Y_{t}$ is the strength perpendicular to the fiber direction in tension, $Y_{c}$ is the strength perpendicular to the fiber direction in compression, and $S_{c 12}, S_{c 13}$, and $S_{c 23}$ are the in-plane shear, and transverse shear strengths, respectively.

- Fiber-matrix shear failure occurs due to a combination of axial stress $\left(\sigma_{11}\right)$ and the shear stresses. The failure criterion has the form:

$$
\begin{aligned}
e_{s}^{2} & =\left(\frac{\sigma_{11}}{X_{c}}\right)^{2}+\left(\frac{\tau_{12}}{S_{c 12}}\right)^{2} \\
& +\left(\frac{\tau_{13}}{S_{c 13}}\right)^{2} \text { for } \sigma_{11}<0
\end{aligned}
$$

and

$$
\begin{aligned}
e_{s}^{2} & =\left(\frac{\tau_{12}}{S_{c 12}}\right)^{2} \\
& +\left(\frac{\tau_{13}}{S_{c 13}}\right)^{2} \text { for } \sigma_{11}>0
\end{aligned}
$$


where $X_{t}$ is the strength along the fiber direction in tension, and $X_{c}$ is the strength along the fiber direction in compression.

- Fiber failure occurs due to tension or compression independent of the other stress component. In compression the fiber fails by buckling. The failure criterion has the form:

$$
e_{f}=\frac{\sigma_{11}}{X_{c}} \text { for } \sigma_{11}<0
$$

and

$$
e_{f}=\frac{\sigma_{11}}{X_{t}} \text { for } \sigma_{11}>0
$$

To simulate the above failure modes, the elastic properties are made to be linearly dependent on three field variables, $F V 1$ through $F V 3$. The first field variable represents the matrix failure, the second the fiber-matrix shearing failure, and the third the fiber buckling failure. The values of the field variables are set to zero in the undamaged state. After a failure index has exceeded 1.0, the associated user-defined field variable are set to 1.0. The associated field variable then continues to have the value of 1.0 , even though the stresses may reduce to values lower than the failure stresses of the material. This procedure ensures that the damaged material does not heal. The mechanical properties in the damaged area are reduced appropriately, according to the property degradation model defined in Table 1. For example, when the matrix failure criterion takes the value of 1.0 , then by the interpolation rule defined in Table 1 , the transverse shear modulus $\left(E_{y}\right)$ and the Poisson ratio $\left(\nu_{12}\right)$ are set equal to zero. The field variables can be made to transit from 0 (undamaged) to 1 (fully damaged) instantaneously. Chang and Lessard's degradation model [4] is used in the present study.

The finite element implementation of this progressive failure analysis was developed for the ABAQUS structural analysis program using the USDFLD user-written subroutine $[12,13]$. ABAQUS calls this USDFLD subroutine at all material points of elements that have material properties defined in terms of the field variables. The subroutine provides access points to a number of variables such as stresses, strains, material orientation, current load step, and material name, all of which can be used to compute the field variables. Stresses and strains are computed at each incremental load step and evaluated by the failure criteria to determine the occurrence of failure and the mode of failure.

\section{Numerical Examples}

To assess the predictive capability of the present failure analysis method, several panels have been analyzed and these results were compared with experimental results. Results are presented for unstiffened panels with and without cutouts and a stiffened panel. The unstiffened panel cases are a flat panel loaded in shear and a curved panel loaded in compression. Results are also presented for a bead-stiffened panel subjected to in-plane shear loading.

Flat Panel Loaded in In-plane Shear

The panels subjected to pure in-plane shear loading were loaded using a picture frame fixture. The test sections of the bead-stiffened and unstiffened panel were 12.0 by $12.0 \mathrm{in}$. in size and the members of the picture frame were 2.75 in. wide and 6.75-in thick. The fixture is made of steel. Figure 1 shows a schematic diagram of a picture frame test fixture. In the finite element model, nodes on each member were constrained for the out-of-plane displacement. Pin joint consists of two co-incident nodes tied in a multi-point constraint at the four corners of the panel. The displacements of the dependent node is made the same as that of the independent node, but the rotations of the co-incident nodes are excluded in the multi-point constraints. The independent node diagonally opposite to the loading pin is constrained for axial and transverse displacements. At the loading pin, applied displacement equal in magnitude in the axial and transverse directions at the independent node simulates the loading condition. The test section is modeled using ABAQUS four node, reduced integration, shear deformable S4R element [13]. The members of the picture frame are modeled using ABAQUS four node shear deformable S4 element [13].

The flat unstiffened panel has a laminate stacking sequence of $[ \pm 45 / 0 / 90]_{2 s}$, with a ply thickness of 0.0056 -in. and is made of graphite epoxy. The mechanical properties for the material are $E_{11}=18.5 \mathrm{Msi}, E_{22}=1.64$ Issi, $G_{12}=G_{13}=0.87 \mathrm{Msi}, G_{23}=0.55 \mathrm{Msi}$, and $\nu_{12}=0.3$. The strength allowables are $X_{t}=232.75$ $\mathrm{ksi}, X_{c}=210.0 \mathrm{ksi}, Y_{t}=14.7 \mathrm{ksi}, Y_{c}=28.7 \mathrm{ksi}$, $S_{c 12}=29.75 \mathrm{ksi}$, and $S_{c 13}=S_{c 23}=4.8 \mathrm{ksi}$. Experimental results for this test panel are reported in Reference [14]. 
A finite element model of the panel is shown in Figure 2. This model consists of 3425 nodes and 3300 elements. An imperfection based on static analysis results for a pressure load was added to the model to simulate an imperfect shape similar to that of a bubble (one half wave in each direction of the panel). Progressive failure analysis (PFA) was carried out for this case with a maximum imperfection magnitude equal to $5 \%$ of the laminate thickness. Three integration points through each ply thickness are used in the analysis for computation of section properties. A post-buckling analysis of the panel with the same level of imperfection was also performed.

The results for the flat panel loaded in shear are shown in Figure 3, where the load is plotted versus the strain normal to the fiber direction $\left(\epsilon_{22}\right)$ in the top and bottom ply $\left(45^{\circ} \mathrm{ply}\right)$ at the center of the test specimen. The dashed lines marked FV1, FV2 and FV3 indicate the load level at which damage described by field variable $F V 1$ through $F V 3$ are initiated well into the post buckling regime. These failures are due to severe bending in the region. The thick solid line represents the experimental results and the thin solid line represents the postbuckling analysis results. The solid and open triangles are analytical results for the panel response that indicates progression of failure. The analysis results are in good agreement with the experimental results. The final failure load obtained from the experiment is 54.81 kips, which is $6 \%$ more than the final failure load of approximately $51.5 \mathrm{kips}$ obtained from progressive failure analysis. Damage initiation starts as matrix cracking $(F V 1)$ at a load level of 37.76 kips. Fiber-matrix shear $(F V 2)$, and fiber $(F V 3)$ failure are initiated at the same load level of $\mathbf{4 5 . 3 7}$ kips. This indicates that the structure can carry an additional 17.04 kips (about $30 \%$ of the final experimental load) after matrix cracking has been initiated. Even after the initiation of fiber-matrix shear and fiber failure, the panel continues to carry an additional load of about 9.4 kips ( $17 \%$ of the final experimental load). The post-buckling analysis results diverge from the progressive failure results at a load level that is slightly higher than the load at which initiation of fiber-matrix shear and fiber failure occurs. At that load level the analysis predicts a significant amount of damage that could have led to a considerable loss of panel stiffness.

All the failure modes initiated near the steel supporting fixture close to the region along the diagonal which is in the panel loading direction and propagate in the region close to the diagonal and along the loading direction. Figure 4 shows a fringe plot of matrix cracking $(F V 1)$ in the top ply after the final failure load. The dark contours denote failed regions of the panel. Other damage modes accumulate in approximately the same region as depicted by the plot. These damage locations are consistent with observations from experiments and do not involve delamination failure.

\section{Curved Panel Loaded in Axial Compression}

The curved panel has a laminate stacking sequence of $[ \pm 45 / 0 / 90]_{3 s}$, with a ply thickness of 0.005 -in. The mechanical properties of the material used for the panel are $E_{11}=17.5 \mathrm{Msi}$, $E_{22}=1.51 \mathrm{Msi}, G_{12}=G_{13}=0.78 \mathrm{Msi}, G_{23}=0.55$ $\mathrm{Msi}$, and $\nu_{12}=0.29$. The strength allowables are $X_{t}=206.0 \mathrm{ksi}, X_{c}=206.0 \mathrm{ksi}, Y_{t}=8.9 \mathrm{ksi}, Y_{c}=17.8$ $\mathrm{ksi}, S_{c 12}=18.3 \mathrm{Ksi}$, and $S_{c 13}=S_{c 23}=4.8 \mathrm{ksi}$. Experimental results for this test are reported in Reference [15].

The panel geometry, boundary conditions and loading are shown in Figure 5. The panel finite element model consists of 6561 nodes and 6400 elements. Measured geometric imperfection from a typical test specimen was included in the model. Three integration points through each ply thickness are used in the analysis for computation of section properties.

The results for the curved panel loaded in compression are shown in Figure 6, where the load is plotted against the end shortening displacement. The filled symbols representing FV1, FV2, and FV3 indicate the load level at which damage described by field variable $F V 1$ through $F V 3$ are initiated. The analysis and expermental results are in good agreement. The final failure load from the experiment is 51.25 kips, which is $11 \%$ less than the final failure load obtained from progressive failure analysis of about $56.8 \mathrm{kips}$. All damage modes initiate after the panel buckling and attaining its final load bearing capability. Matrix cracking $(F V 1)$ initiated at a load level of 43.31 kips just after buckling. Fiber-matrix shear $(F V 2)$ and fiber failure $(F V 3)$ initiated at a load level of $37.53 \mathrm{kips}$ and a load level of 38.32 kips, respectively.

Figure 7 (a) through 7 (c) show fringe plots for matrix cracking $(F V 1)$, fiber matrix shear ( $F V 2$ ), and fiber failure ( $F V 3)$ in the bottom ply after final failure at an applied displacement of approximately 0.1 -in.. Damage initiated within 
than the experimental failure load. Damage initiation starts as fiber-matrix shear (FV2) and fiber $(F V 3)$ failure at the same load level of 28.34 kips. Matrix cracking $(F V 1)$ is initiated at a load level of 30.22 kips. Hence the curved panel can carry an additional load of about 11.0 kips (about $27 \%$ of the final experimental load) after initiation of fiber-matrix shear and fiber failure. After matrix cracking has been initiated, the panel can carry an additional load of 9.0 kips (about $23 \%$ of the final experimental load).

All the failure modes initiated near the edge of the cutout. Figure 12 shows a fringe plot for matrix cracking $(F V 1)$ in the bottom ply after the final failure load. These damage locations are consistent with experimental observations. However experimental observation indicated significant delamination around the cutout. Although the initial geometric imperfection are accurately represented here, the delamination damage may be responsible for the discrepancy between the analytical and experimental failure loads with the panel exhibiting a catastrophic failure with no residual strength.

\section{Bead-stiffened Panel Loaded in Shear}

The thermoformed bead-stiffened configuration is an advanced concept for stiffened graphite thermoplastic panels. Thermoforming ia a cost effective manufacturing method for incorporating bead stiffeners. An experimental and analytical investigation of these bead-stiffened panels was conducted by Rouse [17]. The bead-stiffened panels were loaded in in-plane shear loading using a picture frame fixture similar to the one described above. It was found that the bead stiffened panels failed near the curved tip of the stiffener where large magnitudes of stress resultants were predicted.

The bead-stiffened panel has a laminate stacking sequence of $[ \pm 45 / \pm 45 / 0 / \pm 45 / 90]_{s}$ with a ply thickness of 0.005 -in. The mechanical properties of the material are $E_{11}=18.0$ Msi, $E_{22}=1.50 \mathrm{Msi}, G_{12}=G_{13}=G_{23}=0.82 \mathrm{Msi}$. The allowables are $X_{t}=300.0 \mathrm{ksi}, X_{c}=210.0 \mathrm{ksi}$, $Y_{t}=13.0 \mathrm{ksi}, Y_{c}=31.0 \mathrm{ksi}, S_{c 12}=27.0 \mathrm{Ksi}$, and $S_{c 13}=S_{c 23}=5.0 \mathrm{ksi}$. A finite element model of the bead-stiffened panel is shown in Figure 13. This model consists of 2935 nodes and 2849 elements. No geometric imperfection was added to the model of the bead-stiffened panel. Three integration points through each ply thickness are used in the analysis for computation of section properties.
The results for this in-plane shear-loaded panel are shown in Figure 14, where the load is plotted versus the axial strain $\left(\epsilon_{x x}\right)$ in the top and bottom plies $\left(45^{\circ} \mathrm{ply}\right)$ at the center of the test panel. The curves FV1, FV2, and FV3 indicate the load level at which damage modes described by the field variable $\mathrm{FV} 1$ through $\mathrm{Fl}_{3}$ initiate. The analyses results are in good agreement with the experimental results. The final failure load obtained from the experiment is 27.9 kips, which is $12 \%$ less than the final failure load obtained from the progressive failure analysis of about 24.4 kips. Damage initiation starts as matrix cracking ( $F V 1)$ at a load level of 10.8 kips, whereas fiber-matrix shear $(F V 2)$ and fiber failure are initiated at the same load level of 12.8 kips. Hence the structure can carry an additional load of approximately $17.0 \mathrm{kips}(60 \%$ of the final experimental load) after matrix cracking damage has been initiated. Even after initiation of fibermatrix shear and fiber failure, the panel can carry an additional load of approximately 15.0 kips ( $53 \%$ of the final experimental load).

Figure 15(a) through 15(c) show fringe plots for matrix cracking, fiber-matrix shear, and fiber failure in the top ply after the final failure load. The damage initiated near the curved tip of the bead-stiffener and propagated to the other regions as shown in these figures. The locations for damage are consistent with experimental observations. For the case of this stiffened panel initial geometric imperfections are not a critical factor in predicting the observed behavior.

\section{Concluding Remarks}

The results of an analytical and experimental study to evaluate the initiation and progression of damage in nonlinearly deformed stiffened and unstiffened panel are presented. These studies are also conducted for panels with cutouts and subjected to two loading conditions. The progressive failure methodology includes matrix cracking, fiber-matrix shear, and fiber failure, but ignores delamination failure. The effect of initial geometric imperfections is also investigated as part of the study.

For a flat panel loaded in in-plane shear loading, the three failure modes considered in the study accurately represent the damage senario in the postbuckling regime. The analytically determined response, failure modes and damage locations compare well with the experimental results when the initial geometric imperfection is included in the analysis in a simple manner. When 
a cutout is introduced, however, delamination occurs at the hole boundary as an additional failure mode resulting in some discrepancies with the observed behavior. The analysis results also predict a residual strength with the final failure load being approximately $10 \%$ greater than the experimental failure load.

The response of curved panels with and without cutouts are studied when loaded in compression. With measured geometric imperfection included in both curved panel models, the response of the panel without cutout compares well with experimental results. No delamination occurs for this case and the failure modes considered in this paper develop after buckling. For the curved panel with a cutout, however delamination does occur with the panel failing catastrophically. Unlike the panel without a cutout, this panel with a cutout exhibits no residual strength. It may be important to include delamination failure mode to predict the residual strength of curved panels with a cutout of the type considered here.

The bead-stiffened panel response, failure modes and damage locations are well predicted by the analysis results. The residual strength values from the analysis and experiment are within 12 percent with no geometric imperfection included in the analysis.

\section{References}

[1] Talreja, R., "Modeling of Damage Development in Composites using Internal Variable Concepts," Damage Mechanics in Composites, AD Vol. 12, Proceedings of the ASME Winter Annual Meeting, Boston, MA, 1987, pp. 11-16.

[2] Allen, D. H., Harris, C., and Groves, S. E., "A Thermomechanical constitutive Theory for Elastic Composites with Distributed Damage, Part I. Theoretical Development," International Journal of Solids and Structures, Vol. 23, No. 9, 1987, pp. 1301-1318.

[3] Chang, F.-K., and Chang, K. Y., "A Progressive Damage Model for Laminated Composites Containing Stress Concentrations," Journal of Composite Materials, Vol. 21, Sept. 1987 , pp. $834-855$.
[4] Chang, F.-K., and Lesard, L. B., "Damage Tolerance of Laminated Composites Containing an Open Hole and Subjected to Compressive Loadings: Part 1-Analysis," Journal of Composite Materials, Vol. 25, Jan. 1991, pp. 2-43.

[5] Davila, C. G., Ambur, D. R., and McGowan, D. M., "Analytical Prediction of Damage Growth in Notched Composite Panels Loaded in Compression," Journal of Aircraft, Vol. 37, No. 5, pp. 898-905.

[6] Minnetyan, L., Chamis, C. C., and Murthy, P. L., "Damage and Fracture in Composite Thin Shells," NASA TM-105289, Nov., 1991.

[7] Averill, R. C., "A Micromechanics-Based Progressive Failure Model for Laminated Composite Structures," Proceedings of the 33rd AIAA/ASME/ASCE/AHS/ASC Structures, Structural Dynamics, and Materials Conference, AIAA, Washington, DC, 1992, pp. 2898-2904.

[8] Moas, E., "Progressive Failure Analysis of Laminated Composite Structures," Ph.D Dissertation, Engineering Mechanics Dept., Virginia Polytechnic Inst. and State Univ., Blackburg, VA 1996.

[9] Sleight, D. W., Knight, N. F. Jr., and Wang, J. T., "Evaluation of a Progressive Failure Analysis Methodology for Laminated Composite Structures," Proceedings of the 38th AIA A/ASME/ASCE/AHS/ASC Structures, Structural Dynamics, and $M a-$ terials Conference, Reston, VA, 1997, pp. 2257-2272.

[10] Gummadi, L. N. B., and Palazotto, A. N., "Progressive failure Analysis of Composite Shells considering Large Rotations," Composite Part B, Vol. 29, 1998, pp. 547-563.

[11] Hashin, Z., "Failure Criteria for Unidirectional Fiber Composites," Journal of Applied Mechanics, Vol. 47, June 1980, pp. 329334.

[12] ABAQUS User's Manual, Vol. 3, Ver. 5.6, Hibbitt, Karlsson, and Sorensen, Pawtucket, RI, 1996, pp. 25.2.33-1.

[13] ABAQUS Example Problems Manual, Vol. 1, Ver. 5.5, Hibbitt, Karlsson, and Sorensen, Pawtucket, RI, 1995, pp. 3.2.25.25-1. 
[14] Rouse, M., "Post Buckling of Flat Unstiffened Graphite-Epoxy Plates Loaded in Shear," Presented at the AIA.A/AS.ME/ASCE/AHS 26th Structures, Structural Dynamics, and Materials Conference, Orlando, Florida, April 15-17, 1985. Also AIAA Paper No. 85-0771-CP.

[15] Hiburger, M. W., Britt, V. O., and Nemeth, M. P., "Buckling Behavior of Compression-loaded Quasi-isotropic Curved Panel with a Circular Cutout," 40th AIAA/ASME/ASCE/AHS/ASC Structures, Structural Dynamics and Materials Conference, St. Louis, MO, Paper AIAA99-1279, April 12-15, 1999.

[16] Rouse, M., "Effect of Cutouts or Low-speed Impact Damage on the Postbuckling Behavior of Composite Plates Loaded in Shear," Presented at the AIAA/ASME/ASCE/AHS 31th Structures, Structural Dynamics, and Materials Conference, Long Beach, California, April 2-4, 1990. Also AIAA Paper No. 90-0966-CP.

[17] Rouse, M., "Structural Response of Beadstiffened Thermoplastic Shear Webs," First NASA Advanced Composite Technology Conference, Oct. 29-Nov. 1, 1990., NASA Conference Publication 3104, pp. 969-977.
Table 1: Dependence of material elastic properties on the field variables

\begin{tabular}{llll}
\hline \hline $\begin{array}{l}\text { No } \\
\text { failure }\end{array}$ & $\begin{array}{l}\text { Matrix } \\
\text { cracking }\end{array}$ & $\begin{array}{l}\text { Fiber-matrix. } \\
\text { shear }\end{array}$ & $\begin{array}{l}\text { Fiber } \\
\text { failure }\end{array}$ \\
\hline$E_{11}$ & $E_{11}$ & $E_{11}$ & $E_{11} \rightarrow 0$ \\
$E_{22}$ & $E_{22} \rightarrow 0$ & $E_{22}$ & $E_{22} \rightarrow 0$ \\
$\nu_{12}$ & $\nu_{12} \rightarrow 0$ & $\nu_{12} \rightarrow 0$ & $\nu_{12} \rightarrow 0$ \\
$G_{12}$ & $G_{12}$ & $G_{12} \rightarrow 0$ & $G_{12} \rightarrow 0$ \\
$G_{13}$ & $G_{13}$ & $G_{13} \rightarrow 0$ & $G_{13} \rightarrow 0$ \\
$G_{23}$ & $G_{23}$ & $G_{23}$ & $G_{23} \rightarrow 0$ \\
\hline$F V 1=0$ & $F V 1=1$ & $F V 1=0$ & $F V 1=0$ \\
$F V 2=0$ & $F V 2=0$ & $F V 2=1$ & $F V 2=0$ \\
$F V 2=0$ & $F V 3=0$ & $F V 3=0$ & $F V 3=1$ \\
\hline \hline
\end{tabular}



Figure 1 Schematic diagram of picture frame test fixture.

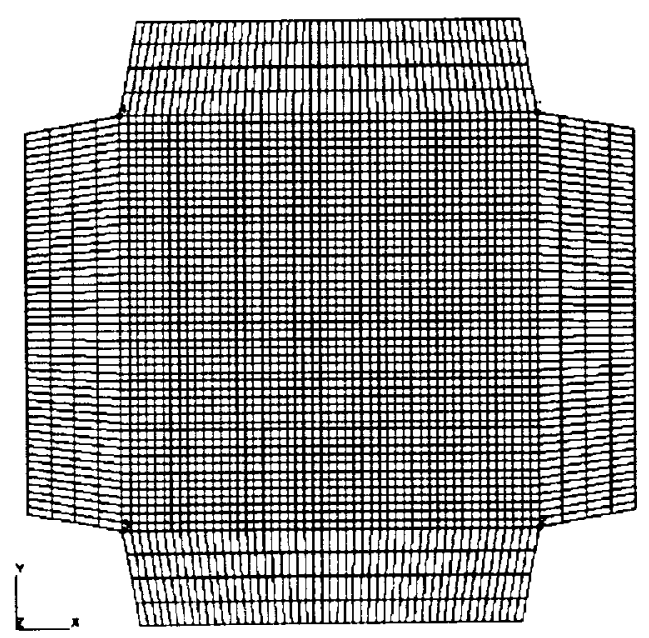

Figure 2 Finite element model of a flat composite panel in the picture frame test fixture. 


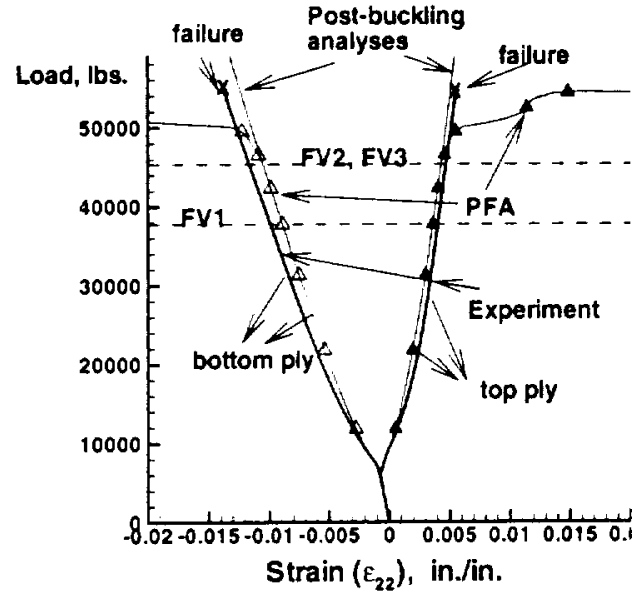

Figure 3 Load vs. strain component normal to fiber direction in top and bottom plies of flat panel loaded in the picture frame test fixture.

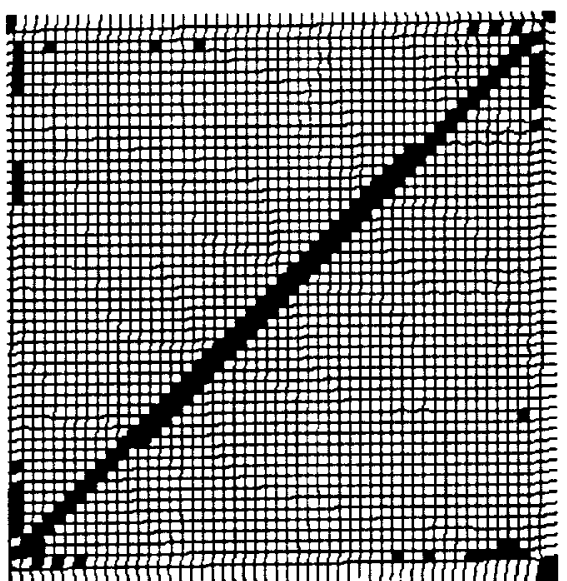

Figure 4 Fringe plot for matrix cracking (FV1) in the top ply of the flat panel.

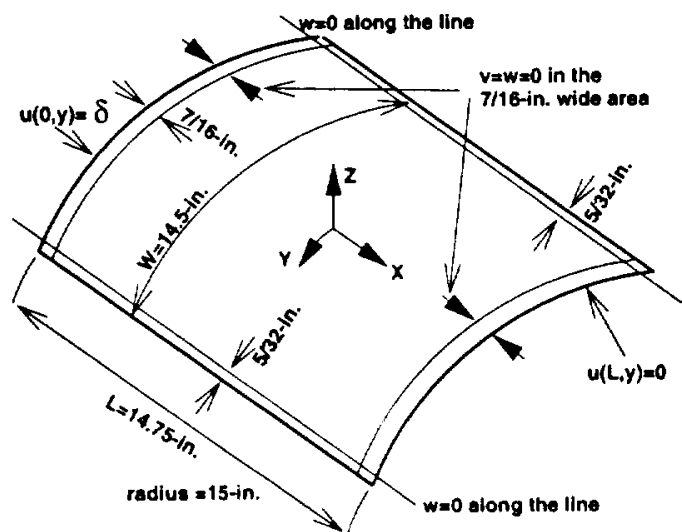

Figure 5 Geometry and boundary conditions for curved composite panel.

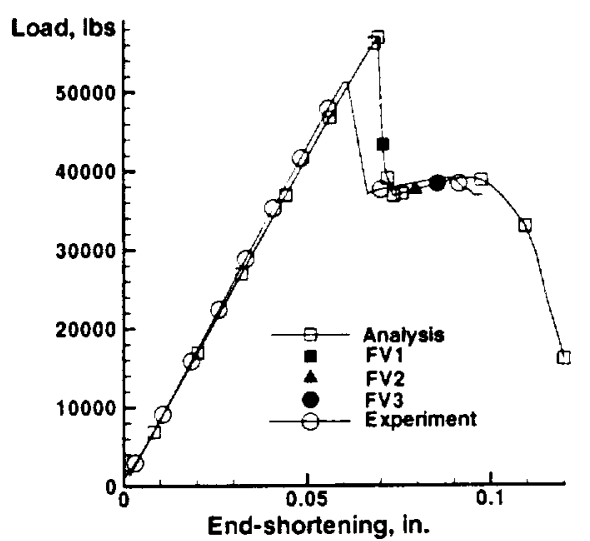

Figure 6 Load vs. end-shortening displacement results for curved panel loaded in compression.

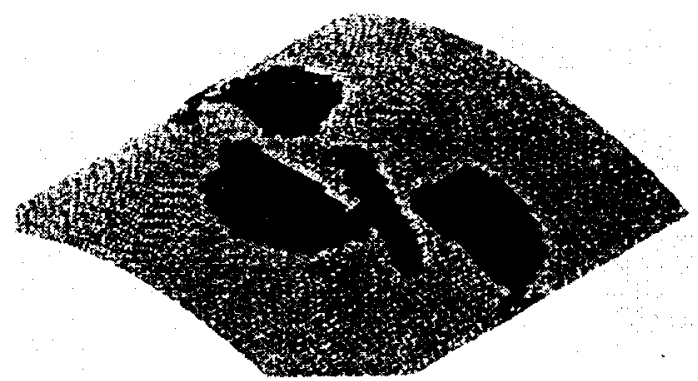

Figure 7(a) Fringe plot for matrix cracking in the bottom ply for curved panel loaded in compression.

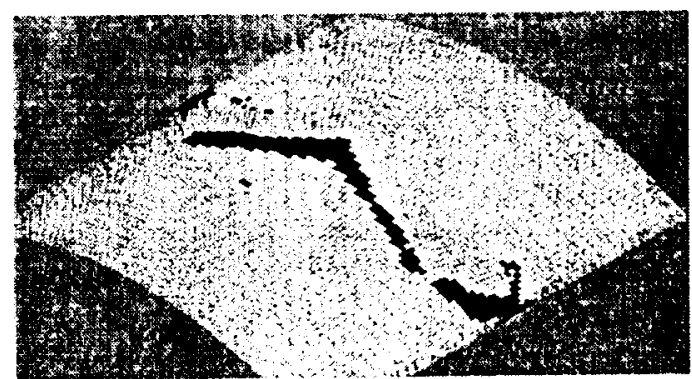

Figure 7(b) Fringe plot for fiber-matrix shear in the bottom ply for curved panel loaded in compression. 


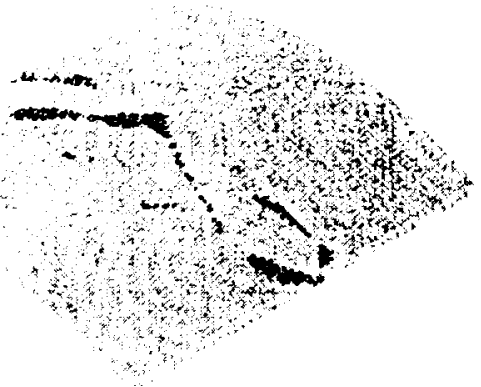

Figure 7 (c) Fringe plot for fiber failure in the bottom ply for curved panel loaded in compression.

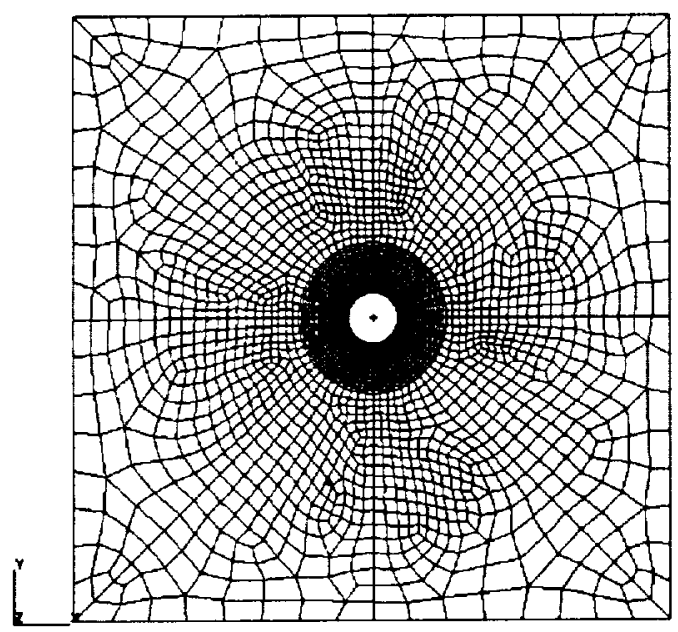

Figure 8 Finite element model of flat panel with a circular cutout.

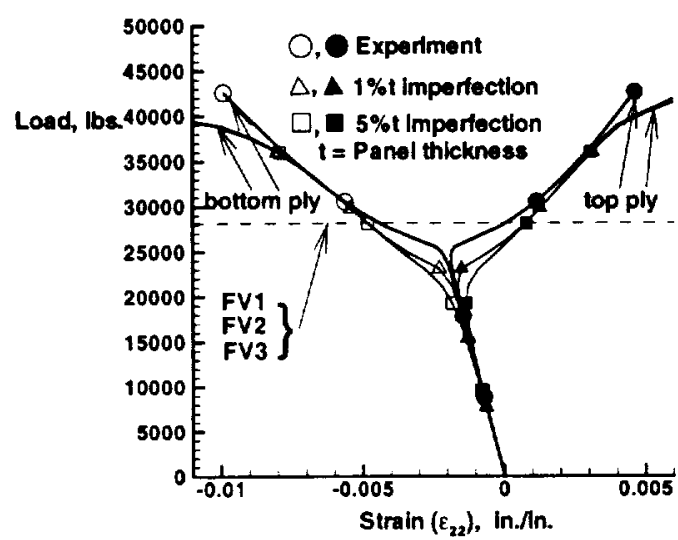

Figure 9 Load vs. strain component normal to fiber direction in the top and bottom plies of flat panel with a cutout loaded in the picture frame test fixture.

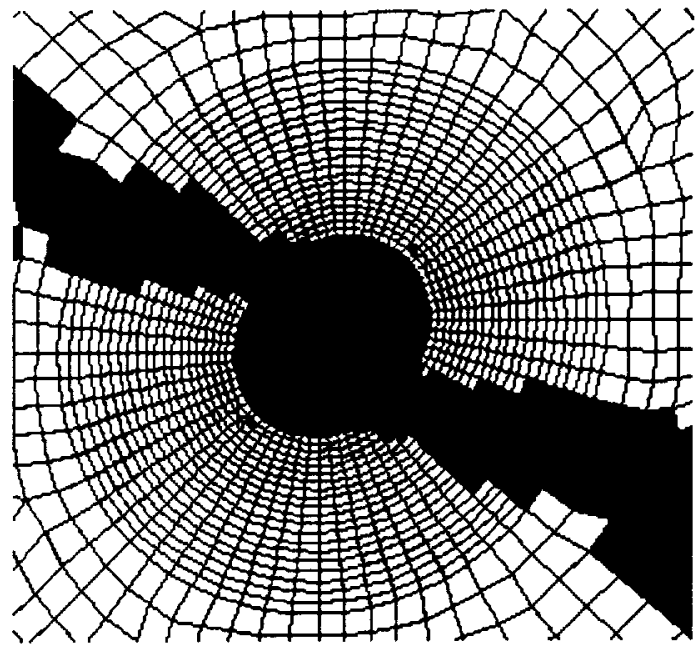

Figure 10 Fringe plot for fiber failure in the top ply for the flat panel with a cutout loaded in the picture frame test fixture.

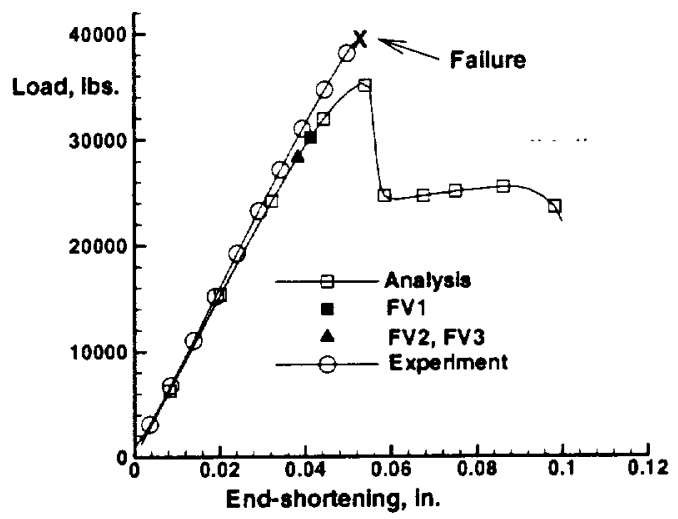

Figure 11 Load versus end-shortening displacement for a curved panel with cutout $(d / W=0.2)$ and subjected to axial compression loading.

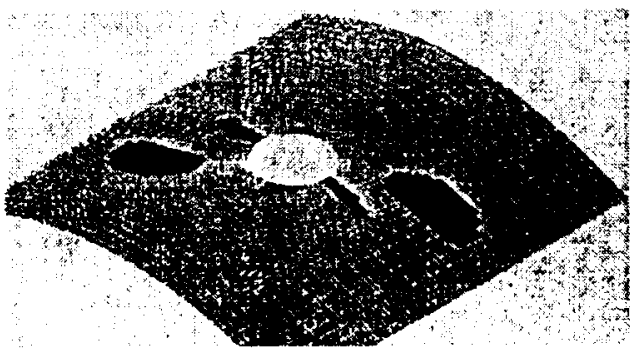

Figure 12: Plot for matrix cracking damage in the bottom ply for curved panel with cutout $(d / W=0.2)$ and loaded in compression. 


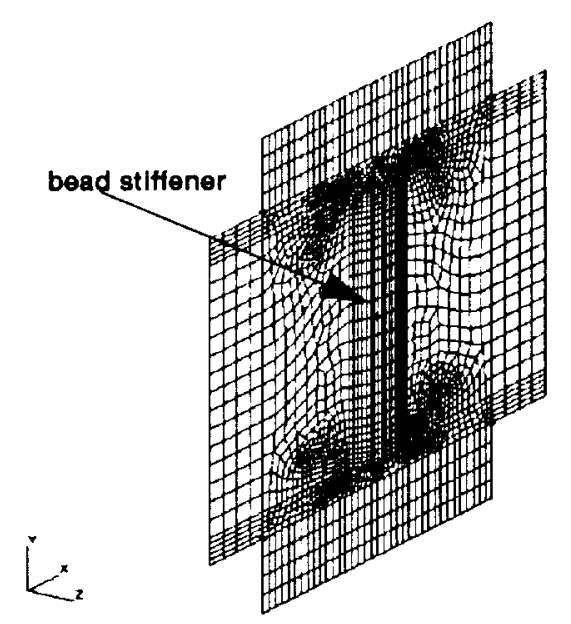

Figure 13: Finite element model of the bead-stiffened panel in picture frame test fixture.

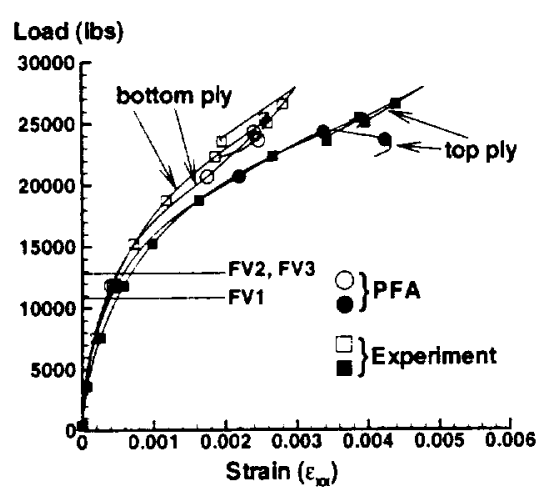

Figure 14: Load versus axial strain, $\left(\epsilon_{x x}\right)$ results at the center of bead-stiffened panel.

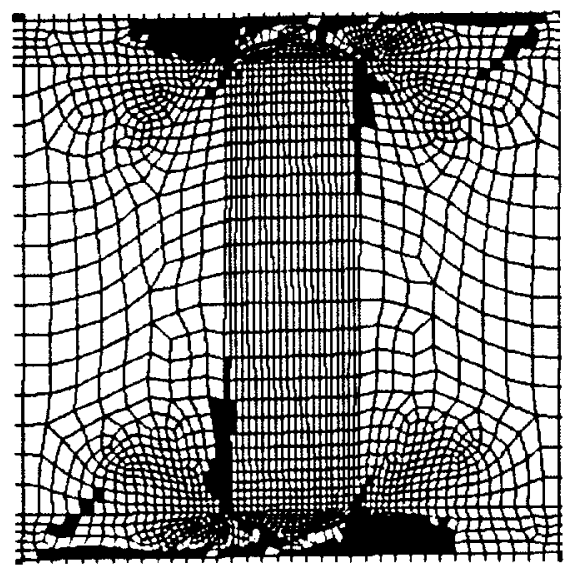

Figure 15(a) Fringe plot for matrix cracking in the top ply of the bead-stiffened panel

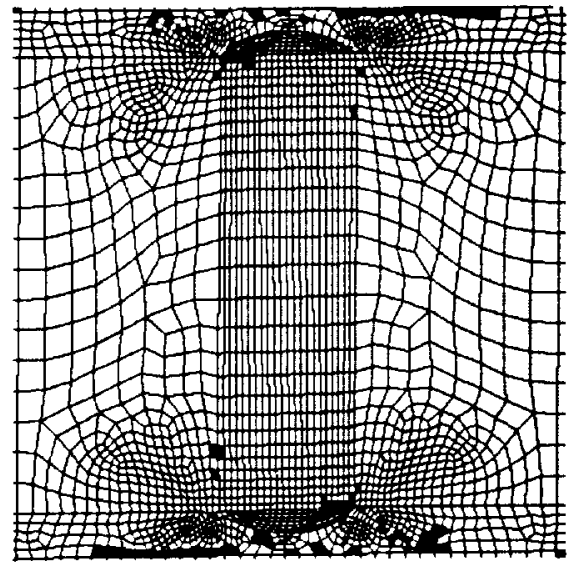

Figure 15(b) Fringe plot for fiber-matrix shear in the top ply of the bead-stiffened panel

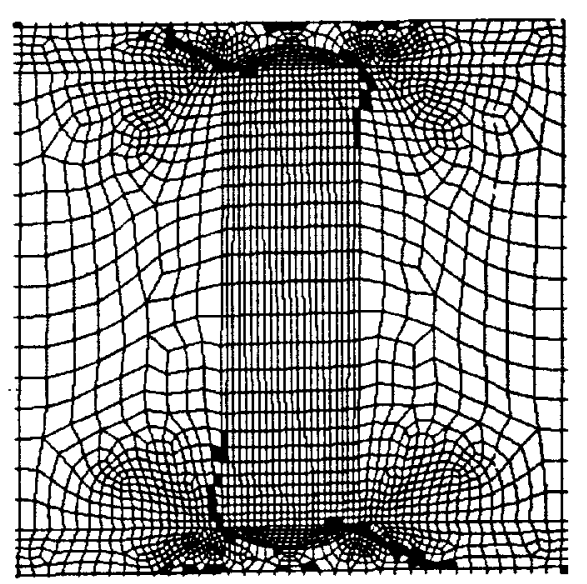

Figure 15(c) Fringe plot for fiber failure in the top ply of the bead-stiffened panel 
July 26, 2001

\section{NASA STI Acquisitions DAA Authorization}

The following papers (copies enclosed) have been DAA approved as Unclassified, Publicly Available documents:

\section{Meeting Presentations:}

42nd AIAA/ASME/ASCE/AHS Structures, Structural Dyn..., 4/16-19/2001, Seattle, WA:

T.F. Johnson, et al.: High Temperature Polyimide Materials in Extreme Temperature...

D.A Russell, et al.: Effects of Electrons, Proton, and Ultraviolet Radiation on Thermo...

J. Arbocz, et al:: On the Accuracy of Probabilistic Buckling Load Predictions.

J. Arbocz, et al: On a High-Fidelity Hierarchical Approach to Buckling Load Calculations.

M.P. Nemeth: Buckling Behavior of Long Anisotropic Plates Subjected to Fully...

D.R. Ambur, et al.: Progressive Failure Studies of Composite Panels With and Without...

M.W. Hilburger, et al:: High-Fidelity Nonlinear Analysis of Compression-Loaded...

M.W. Hilburger, et al:: Nonlinear Analysis and Scaling Laws for Noncircular Composite...

M.W. Hilburger, et al.: Nonlinear and Buckling of Curved Panels Subjected to Combined...

J.C. Newman, et al.: A Review of the CTOA/CTOD Fracture Criterion - Why it Works.

10th AIAA/NAL-NASDA-ISAS Int'l Space Plane \& Hypersonic..., 4/24-27/2001, Kyoto, Japan:

C.R. McClinton, et al:: Hyper-X Program Status.

American Helicopter Society 57th Annual Forum, 5/9-11/2001, Washington, DC:

M.L. Wilbur, et al.: Vibratory Loads Reduction Testing of the NASA/ARMY/MIT Active... 7th AIAA/CEAS Aeroacoustics Conference, 5/28-30/2001, Maastricht, The Netherlands:

L. Maestrello: Laminarization of Turbulent Boundary Layer on Flexible and Rigid Structures. 15th AIAA Computational Fluid Dynamics, 6/11-14/2001, Anaheim, CA:

D. Sidilkover, et al: Factorizable Upwind Schemes: The Triangular Unstructured Grid...

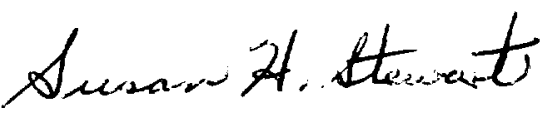

Susan H. Stewart

DAA Representative

NASA Langley Research Center

Mail Stop 196

s.h.stewart@larc.nasa.gov

phone: (757) 864-2518

fax: (757) $864-2375$

Hampton, VA 23681-2199 